\title{
Monitoring and Evaluation Preparedness of Public Sector Institutions in South Africa
}

\author{
C.E. Eresia-Eke ${ }^{1, *}$ and E.S. Boadu ${ }^{2}$ \\ ${ }^{1}$ University of Pretoria, South Africa \\ ${ }^{2}$ University of the Western Cape, South Africa
}

\begin{abstract}
In a bid to improve service delivery in South Africa, the government has created a government-wide monitoring and evaluation (M\&E) system that would help gauge performance across all spheres of government. This has compelled public sector institutions to adopt and implement M\&E systems mandatorily, even when they are not necessarily ready for it. The unpreparedness inevitably perforates the ability of M\&E systems to credibly support performance improvement in public sector institutions and it is problematic. To some extent, the practice of M\&E in the public sector seems to be for purposes of compliance rather than the ideal of performance improvement. This qualitative study investigates the readiness of South African public sector institutions for M\&E, through the perspectives of Managers primarily in the M\&E space. Findings reveal mixed signals of M\&E readiness. For instance, the factors motivating the creation of the M\&E system and the calibre of staff championing it, seem to suggest M\&E readiness. Conversely, the non-availability of capacity to support the system and the potential response of staff to negative information generated by M\&E signal non-readiness. The import of this is that readiness assessments specific to institutions have to be conducted as a basis for determining areas where the prerequisites for M\&E are lacking. This should then inform remedial efforts that ultimately help to improve the potency of the M\&E system.
\end{abstract}

Keywords: Monitoring, Evaluation, Readiness assessment, Public sector, Performance management.

\section{INTRODUCTION}

South Africa repeatedly experiences incidents of citizen discontent often expressed in the form of what has become known as 'service-delivery' protests. The service delivery protests usually stem from frustrations felt by citizens with the absence of basic services and slow or non-existent infrastructural development by the government. The frustrations are fanned by the high levels of poverty and unemployment amongst a large portion of the South African population. Eresia-Eke and Okerue (2018) acknowledge that the unemployment level in South Africa is high and it has consequently become the people's bane. In the light of this, the prominent place of poor service delivery in the scheme of citizen dissatisfaction cannot be ignored. This is why poor service delivery remains a concern not only to the people but also to the government of South Africa.

To address the situation, it would seem rational to expect that the overall performance of state institutions would need to improve. This is because such an improvement is likely to engender better socioeconomic conditions for the people. Abrahams (2014) observes that the South African government is under intense pressure to deliver services to the needy population. So the non-negotiable deal has to be that

*Address correspondence to this author at the University of Pretoria, South Africa; Tel: 0124205295; Fax: 0865110954;

E-mail: Chuks.eresia-eke@up.ac.za governments across the National, Provincial and Municipal spheres continually strive for better performance.

To further the pursuit of higher levels of performance, the need for effective monitoring and evaluation of government initiatives has become amplified. Cloete (2009) recognises monitoring and evaluation (M\&E) as integral parts of a management process that have to be undertaken in order to achieve success. Matsiliza (2012) argues that monitoring and evaluation can also promote accountability in the public sector. This reality has encouraged the South African government to develop what it refers to as a Government-wide monitoring and evaluation system (GWM\&ES) which according to Ile, Eresia-Eke and Allen-lle (2019) is a signal of the South African government's preference for a participatory M\&E approach. The GWM\&ES comprises three complementary frameworks of Programme performance, Evaluation policy and Statistical quality. These frameworks are credited to the National Treasury, the Department of Performance Monitoring and Evaluation and Statistics South Africa, respectively.

While the system of M\&E may be in place in South Africa, the recurrent service delivery protests that dot its landscape could be an indication that the levels of performance of government as gauged by citizen satisfaction remains wanting. This situation is certainly 
discomforting and it is against this background that this study elects to explore the preparedness of public sector institutions for the M\&E system created by the government. The motivation derives from a conviction that if existing M\&E systems are doing what they ought to be doing, then public sector performance in South Africa should be on an upward trajectory. If the M\&E systems are instituted and they are not aiding increased performance, then, it begs the question of whether the necessary pre-requisites for effective M\&E exist in these institutions. For surely, in the case of the absence of the pre-requisites, the entire M\&E system would become merely an ornament with aesthetic appeal rather than a mechanism that delivers functional value. The study, therefore, investigates the readiness of public sector institutions to execute M\&E, recognising that it is the first step towards enhancing overall performance through evidence-based decisionmaking in government.

\section{LITERATURE REVIEW}

Inefficiencies in the public sector constitute major impediments to the political, social and economic growth of nations, especially on the African continent. It is therefore unsurprising that effective public sector reforms have been touted as a possible remedy for some of the developmental challenges in Africa that are linked to public sector performance. There is no gainsaying the fact, that public sector reforms can differ broadly and so a certain degree of vagueness attends the discourse on what exactly constitutes a public sector reform. Similarly, the population is often quite opinionated about which specific aspects of the public sector requires reformation as a means for fostering sustainable development and better living standards for the citizenry. Regardless of the shape and content of such reforms, their potency may well be defined by the extent to which the performance of such reforms is tracked, assessed and documented.

Much of this is only possible when the organs of the state have put in place the prerequisites for the smooth functioning of a performance management mechanism. Essentially, a critical component of this performance management mechanism is the M\&E system. Kusek \& Rist (2002) aver that a thorough readiness assessment is a necessary precursor for the development of an effective and efficient result-based M\&E system. In agreement with this thought, Mackay (2007) affirms that a readiness assessment provides a solid foundation for the M\&E system. While previous studies
(Kusek, 2011; Castro, Lopez-Acevedo, Busjeet and Ordonez, 2009; Lahey, 2005), have largely focused on M\&E readiness assessment of countries in the global south, not much has been done in this regard, in the African continent.

South Africa, very much like some other African countries, is still in the process of developing and nurturing an efficient and effective result based monitoring and evaluation system. The haste on the part of most African governments is informed by the notion that a well-structured results-based M\&E system has the potential to enhance the delivery of service by public officials as part of the drive for public sector reforms. For reforms to be efficacious, the role of clear roadmaps cannot be overemphasized. It is in this context that a readiness assessment for an M\&E system becomes critical. Without a readiness assessment, the foundation for the M\&E system may be shaky as Kuzek and Rist (2004) opine that it is an important phase of building an M\&E system that is so often ignored.

Besides, conducting a readiness assessment (to serve as the point of reference), the processes towards adopting a specific national results-based M\&E system can benefit from legislative and leadership backing. Therefore, due attention needs to be paid to some social, political and economic dynamics (the existing regulatory or legislative frameworks, leadership, M\&E structures and systems, capacity building among others), in order to mitigate any unintended challenges. Erstwhile studies have sought to argue that, there are some underlying factors across most developing countries that hamper the development and implementation of an effective M\&E system (Gomez, Olivera and Velasco, 2009; Boadu and Ile, 2017).

The drive on the part of leadership to develop, commit and champion M\&E culture at the national and local levels by providing legislative support and incentives in national and sub-national budgets has been identified as key in the design and building of a national results-based M\&E system (Enjela and Ajam, 2010). On a similar note, the take of Kusek and Rist (2004) is that the readiness assessment can easily be conducted, if the political leadership drives the course from the national level. This, of course, presupposes that the political leadership understands and appreciates the usefulness of a readiness assessment for an M\&E system. Indeed, beyond just the political leadership, the main arms of government, the media and civil society can all play key roles in developing, 
and enhancing governance systems (Kusek and Rist, 2003), of which a results-based M\&E system is an integral part.

The road toward the institution of an M\&E system can be dotted by challenges. Some of the obstacles that obstruct the runway for a good M\&E system as acknowledged by some scholars include the lack of political will, inadequate M\&E capacity, insufficient material and human resources, weak technical knowhow, poor M\&E capacity-building in most government institutions (Gomez, Olivera and Velasco, 2009). In concurrence with this thought, Lahey (2005) isolates the lack of political will on the part of the government as well as inadequate institutional competencies as the major hiccups linked to the development of efficient and effective results-based M\&E systems. To be sure, in the specific South African context, it may be issues like this that a proper readiness assessment can reveal; so that the relevant authorities would subsequently address whatever shortcomings have been identified. This way, the M\&E system is likely to be more effective and useful as a factor in the public sector reform equation.

Overall, a readiness assessment really seeks to establish if the prerequisites for a good M\&E system are in place within the organization. Needless to say, the absence of the prerequisites can only mean that the M\&E system could be in existence but its functionality would be significantly hampered. While seeking to determine if an organisation is ready or not, for M\&E, attention is paid to issues like the existence of incentives for performance information within the organization. On this score, Lahey (2005) posits that incentives actually stimulate the culture of M\&E information generation and utilization for learning purposes, amongst others. Certainly, it would seem rational to contend that the commitment of the leadership to support the M\&E system would serve as an important incentive. Such a resolve on the part of the leadership according to Kusek (2011) is critical for the sustainability of the results-based M\&E system.

Preparedness for M\&E can also be signaled by the existence of the appropriate structure that supports the generation of performance information and its application for meaningful decision-making. For instance, Castro et al., (2009) argue that some degree of centralization could ease the pathway for the development of an effective and efficient M\&E system. It might be in response to this assertion that the government of South Africa has created a seemingly centralised government-wide monitoring and evaluation system (GWM\&ES). Perhaps the advocacy for the centralised structure emanates from a belief that such a structure would enable better integration and coordination of performance information across government in order to ease access and enhance the utility of the information that the system provides.

The establishment of an effective M\&E system and its continued sustainability is fraught with challenges, especially in territories where the notion of M\&E is still largely in its embryonic stages, as is the case in Africa. In the African continent, issues such as poor M\&E structures, disjointed M\&E frameworks, lack of coordination among institutions, lack of knowledge of M\&E, lack of cooperation between evaluators and beneficiaries have been highlighted as prime challenges that confront organizations and governments as they strive to construct well-structured M\&E systems (Hauge, 2001; 2003; Koranteng, 2000). All of these can ultimately translate to a weak M\&E culture. These shortcomings, if not addressed, can easily deflate the potential of the M\&E system to support the quest for performance improvement by delivering timeous and credible performance information. Again, to ensure that the benefits of an effective M\&E system crystallize to organisations in the public sector, it is imperative to undertake a readiness assessment.

Within the specific context of the public sector, Lahey (2005) reveals that besides the aforementioned challenges, the necessary technical skills and modern tools to ensure proper functionality of the existing M\&E systems are lacking. The whole point of a readiness assessment is to draw the attention of stakeholders to such issues so that decisions can be made to plug the gaps where they exist. For instance, if an organisation recognizes its shortcoming in terms of necessary human expertise in M\&E, then recourse to the contracting of external technical support can become an attractive consideration. Largely, the readiness assessment, therefore, enables organisations to be proactive rather than reactive to challenges that might negate the effective operation of the M\&E system.

Wagner, Day, James, Kozma, Miller and Unwin (2005) opine that the task of undertaking M\&E in most organizations and government ministries can be daunting. Perhaps this is due to the lack of preparedness on the part of organisations with an intent to institute an M\&E system. Strange, but it would seem like the quest for the development of an M\&E 
system may be more out of a compliance desire or a bandwagon effect than a conviction that the system can engender better performance. A readiness assessment could, therefore, prove essential to a public sector organization as it is likely to generate invaluable information about current M\&E frameworks, the need for the creation of a new system or upgrading the existing M\&E systems. In this regard, Kuzek and Rist (2004) emphasize that the political leadership or managers should be the driving force behind the M\&E system while ensuring the provision of material and human resource to make the system work.

M\&E systems tend to lack the necessary material and human resources (Plaatjies and Porter, 2011) to enable them to function. The situation may even be more serious in the public sector where political considerations are a major part of the traditional base for decision-making and resource allocation. Indeed, the nonexistence of leadership support and institutional readiness for M\&E was observed in six African Countries (Porter and Goldman, 2013). This does not augur well for the M\&E system that is supposed to bear the responsibility of producing facts that communicate how well or poorly an institution is performing. Against this background, it would be difficult to argue that a readiness assessment that highlights the strengths and weaknesses (political and otherwise) of the organisation as it concerns providing needed support to an M\&E system will be of scant value to Managers who are keen on M\&E.

According to Kusek, Rist and White (2005), proper implementation of an M\&E system will require the adoption of a participatory approach with various stakeholders actively demonstrating commitment to the system's sustainability. The M\&E system should embrace collaboration with a wide pool of stakeholders. The non-involvement of stakeholders in the development and maintenance of an M\&E system makes the system, susceptible to failure. Maybe this is the case in Africa, in the light of the opinion of Porter and Goldman (2013) that there are lingering uncertainties intertwined with government efforts to implement M\&E systems across the African continent. The non-involvement of stakeholders may be a fallout of many internal and external factors that inevitably undermine effective collaboration in the scheme of M\&E activities. A readiness assessment, as a diagnostic tool, may place the organisation in a position of knowledge as to what to invest in (or otherwise), to make an M\&E system productive. It could be on the strength of results gleaned from readiness assessment diagnostic exercises that it has been argued that governments in developing countries can enhance service delivery significantly by devoting adequate resources to the M\&E function (Behn, 2003; Benington and Moore, 2011).

This idea of sustaining an M\&E system by ensuring the allocation of adequate resources is given verve by Porter and Goldman (2013) who insist that in most Africa countries, matters bordering on institutional and human resource capacity development for M\&E are typically overlooked. Indeed, Kusek, Rist and White (2005) warn that for proper implementation and sustainability of an M\&E system, the development of institutional capacity that includes technical and human skills are of critical importance. Cognizant of this important task, a proper readiness assessment should unveil skills gaps (or otherwise) for effective operations of the M\&E system. The skills that could court the attention of such an assessment may include but not limited to practical skills in information gathering or collection, data capturing, analysis and proper utilization of M\&E information (Mackay, 2007).

The overwhelming position in extant literature is that there is inadequate human and institutional capacities in developing countries, Africa in particular (SchiavoCampo, 2005) for M\&E. The lack of M\&E training opportunities and networks for M\&E personnel in the majority of government institutions and ministries has been perceived as one of the main drawbacks (Castro et al., 2009; Engela and Ajam, 2010). However, it is noteworthy that some attempts have been made to address the situation in some African countries by institutionalising M\&E networks among government departments and ministries for specialists to strengthen the function in Africa (Segone, 2000). To add impetus to such attempts, it is important to note that an empowering regulatory or legislative framework for M\&E as well as a guide that provides clarity regarding the roles and responsibilities of all stakeholders (Scott, Joubert and Anyogu, 2005) could be crucial.

To cap, a proper analysis of institutional challenges, arguably through a readiness assessment, could be the stepping-stone for the successful development and sustenance of an M\&E system (Pares, 2006). All hiccups identified by a readiness assessment can then be tackled in a bid to ensure that the benefits collateral with having an effective M\&E system crystallize to the organisation. This argument finds an ally in the thought of Hauge (2003) who affirms that if setbacks are identified early and adequate support to overcome 
them is provided by organisations, prior to the establishment of the M\&E system, it would aid the overcoming of some of the difficulties that hamper the M\&E function.

\section{METHODOLOGY}

The study is qualitative research. It was necessary to use the qualitative research approach as it allowed the researchers to obtain in-depth information related to the M\&E preparedness of government institutions from managers. From a philosophical perspective, the interpretive research paradigm was followed in the conduct of the study, which is an indication of the researchers' endorsement of the position that there is no objective knowledge that is unrelated to the reasoning of humans. In essence, for this study, meaning does not exist independently from human consciousness but is rather derived from social constructivism.

A non-probability sampling method was used to select respondents for the study. The choice of respondents was however influenced by the keyinformant technique, which helped to ensure that only practitioners operating in the M\&E space in government participated in the study. Responses were gathered from thirty-five participants, all of whom were managers of different standings in their respective institutions. For a measure of representativeness, respondents were selected from municipal, provincial and national government establishments. It was believed that this would provide a wholesome reflection of the state of preparedness of public sector institutions for M\&E.

Given that the study is qualitative research, the preferred method for collection of responses was through the conduct of interviews. While some of the interviews were telephonic, others were of the face-toface type. The instrument that guided the soliciting of responses was based on Kusek and Rist's (2004) readiness assessment questions that have been used in previous studies for the determination of the M\&E readiness of countries/organisations. The M\&E readiness assessment instrument seeks responses from the study participants for eight issues. These eight issues are related to three broad readiness themes as identified by Kusek and Rist (2004) which include the incentives and demands for performance information, the roles and responsibilities of existing units in the performance information value-chain of an institution and the capacity to support the M\&E effort.

\section{FINDINGS}

The findings of the study are based on the responses of 35 public officials. The public officials were all at managerial levels and they were drawn from 21 different government organisations across the three spheres of government: national, provincial and municipal as well as the metropolitan cities in South Africa. The drive of the government of South Africa for effective programme performance tracking through the GWM\&ES is clearly well-intended but the extent to which the benefits of such a system could crystallize is inextricably linked to the preparedness of government establishments to adopt and entrench the system within organizational policies, programmes and projects that they implement. The absence of the prerequisites for M\&E, even within organisations that already have M\&E systems, may be consequential. The ramifications of such a situation that smacks of poor M\&E preparedness, on the all-important goal of service delivery, can be dire. The inquiry was based on questions probing managers' views using Kusek and Rist's (2004) eight different issues related to the determination of M\&E readiness.

\section{The Precursors for Building M\&E System}

The impetus for building an M\&E system requires some knowledge about the underlying reasons fueling the creation and institution of the M\&E system. In this regard, it was necessary to ask the respondents about the potential pressures that are encouraging the establishment of an M\&E system. Most respondents, though unclear about the pressures, volunteered that the establishment of the M\&E system was compulsory for their various organisations, given that the GWM\&ES enjoys the backing of the executives at the highest levels of authority in the national government. This position was also evident in the submission of some respondents that the establishment of the M\&E system was due to external or internal directives from higher authorities.

In addition to this, some respondents from the municipal level argued that the need to monitor the municipal budget expenditure, allocate resources justifiably and ensure the success of interventions captured in the integrated development plan (IDP) were some of the prime reasons driving the establishment of the monitoring and evaluation system. Others contended that the people's needs for better service delivery, performance feedback as well as the necessity for documentation of the progress of 
interventions were catalysts for the establishment of an M\&E system. Interestingly, there was a suggestion that poor service delivery is due to the incoherence in available results-based information, which subsequently makes it difficult to properly link municipal expenditures to tacit evidence of service delivery. The fieldwork results also revealed that the motivation for the establishment of results-based M\&E system in some government department is as the result of the pressures emanating from government legislative instruments, institutional mandate as well as the call by civil society organization for transparency and accountability.

\section{The Advocate of the M\&E System}

There are always individuals behind the establishment of an M\&E system. These individuals are typically more effective in advocating for M\&E when they are positioned higher up in the authority hierarchy within an organization. So the higher the level of authority of the person(s) driving the establishment of an M\&E system, the more rational it becomes to project that the organization is prepared for M\&E. Empirical evidence gathered on this aspect of M\&E readiness revealed that the majority of the officials interested in the building of an M\&E system in metropolitan municipalities are the city managers, mayors and municipal managers. This bodes well for the state of readiness of the government institutions for M\&E given that the 'right tone' that will support effective M\&E is coming from the top.

There were, however, some cases where the respondents indicated that they did not know any specific person(s) championing the establishment of the M\&E system. This seemed curious but it may be that individuals driving for the establishment of the M\&E are not sufficiently active in canvassing for the M\&E and so they are not easily recognizable as M\&E champions in their organisations. In some cases, the respondents had different opinions about who the champion for M\&E was, in the organisation. In such cases, it may be an indication that no single individual can be credited with the advocacy for the establishment of the M\&E system. On the contrary, the clamour for the system appears to be a subtle current of desire for performance-related information by internal stakeholders in the organisation. This may be a pointer to the emergence of a culture of meaningful performance measurement in government institutions, which possibly spells preparedness for M\&E.

\section{Motivation for Leadership and Champions to Support the M\&E System}

An M\&E system should empower organizational leadership with performance-related information that could enhance decision-making. Respondents indicated that what could be motivating the leaders and champions to support the establishment of an M\&E system can be linked to a realization that it would serve as a veritable aid for more effective and efficient delivery of projects in a way that allows for stakeholders' expectations to be met. The more intense oversight role of the legislative arm of government and the upsurge of investigative journalism were also cited as factors that could be motivating leaders and champions to support the M\&E system. This is simply because the demands made by oversight organs on the institutions, make the development of a system that tracks performance and generates accurate information, imperative.

According to some respondents, leadership support for the M\&E system is not optional. Indeed, they insist that part of the leadership's mandate and function, in government institutions is to ensure that the policy planning and development units, as well as the M\&E office, are in existence. This position may mean that the commitment of the organisation's leadership to effective M\&E can be doubtful as it would appear that the support is not necessarily borne out of willingness and conviction but is rather, just an act of compliance with a mandate.

Another opinion that was canvassed was that the central motivation for any form of support from the leadership/champions stems from recurrent public outcry over poor service delivery and pressure from civil society organisations for accountability. This view seems in alignment with the thought of others, that the support for the performance-based M\&E system is largely because of a pervasive fear of failure to deliver on the promises made by the ruling government, which would negatively affect citizens' confidence in the government. An interesting observation by some respondents, however, was that despite the existence of different motivating forces that engender support for the M\&E system, the extent and honesty of the support provided, remains questionable.

\section{Ownership and Beneficiaries of the M\&E System}

In all of the organisations studied, there was an existing M\&E system that seeks to collect, analyse and 
produce performance information for better policy decision-making and efficient public spending. In a sense, therefore, the need for having an M\&E system seems to be a forgone conclusion and what really remains unclear is whether the organisations are prepared for it. Needless to say, it is one thing to need an M\&E system but it is yet another, to get an organization, ready for the system. The extent of readiness of an organisation contributes to the effectiveness (or lack of it) of the M\&E system. An effective results-based M\&E system should be accessible to both project implementers and target beneficiaries and must have the potential to produce appropriate information and data for policy choices (Kusek and Rist, 2004).

It was evident from the responses that the municipal or local council units for M\&E and programme managers are the owners of the system. In other instances, M\&E officers and city planning and strategic units were said to be the owners of the system. In essence, the ownership of the M\&E is quite localized, internally that is. This is slightly out of alignment with the argument that co-ownership of the M\&E system by implementers, beneficiaries and stakeholders is critical to the effectiveness of the system as it ensures a greater sense of ownership (Ataov and Haider 2006; Cahill, 2007). The current situation where ownership rests with government functionaries is obviously hinged on the assumption that only government employees have the ability to sustain the system. The assumption goes against the contention of Chouinard and Cousins (2013) that a broader ownership structure reflecting participatory M\&E is not only effective but also more beneficial.

With respect to the issue of beneficiaries, study results reveal that apart from a particular government establishment directly benefiting from the M\&E system, other stakeholders also benefit from the system. Some respondents opined that the National Treasury, The Presidency, target beneficiaries, the media, civil society and employees alike were all prominent beneficiaries of the M\&E system. The broad spectrum of beneficiaries of an M\&E system just goes to emphasize the importance of the preparedness of government institutions for the M\&E system. Cognizant of the pool of beneficiaries, failure of the M\&E system that stems from poor readiness of organisations is sure to be a worrisome prospect; for the stakes for performance can be quite high.
M\&E Support for Resource-Allocation and the Quest for Programme Goals

Information related to project implementation, progress, and attainment of outputs, outcomes and impacts are of significant importance in various spheres in the public sector. The prevalent opinion of respondents was that ideally, information generated by the M\&E system should prove useful for tasks of resource allocation and the determination of programme goals. The practice according to some of those who participated in the study is that M\&E information is typically disregarded when budget allocations are being made. This position suggests that the amount of resources allocated to an initiative or government function is inconsiderate of the extent of performance achieved by such initiatives in previous terms. This is troubling because the import is that other factors besides the performance of an intervention dictate resource allocation. In effect, for instance, for two similar projects where one is performing and the other is not, resource allocation may be exactly equal. Such an approach, to some extent, defies business logic. It is akin to rewarding failure and success, equally.

Respondents expressed the opinion that performance information generated by an M\&E system should help government organisations better identify programmes needs and consequently influence the amount of resources necessary for each programme. Managers reiterated that a good result-based M\&E system should assist in the optimal and equitable distribution of resources if the information generated is taken seriously.

As it concerns the issue of programme goals, the opinion of most respondents was that M\&E information had no bearing on the goals set for programmes. The goals, they say, are often fallouts of citizen concerns rather than M\&E recommendations. This position seems to preclude the fact that M\&E information can be useful for the purposes of planning. For instance, by considering M\&E information, project directors should be able to make more informed decisions regarding the project design, implementation and other equally important activities timeously to minimise project interruptions and to achieve the intended objectives. Morra Imas and Rist (2009) aver that a well-established result based M\&E system has the potential to enable better project planning and goal-setting.

The fieldwork obtained responses, which reveal that an M\&E system should help to identify, assess, monitor 
and manage available human, financial and other resources to achieve desired results. The research findings conform to the reasoning of United Nations Development Programme (2009) that an effective and efficient M\&E system has the potential to identify whether targets associated with a particular project have been achieved as planned or not. Regardless of this, the reality as evidenced from the responses obtained by the study is that the influence of the M\&E system on issues of resource allocation and determination of programme goals, is scant if not completely non-existent. This situation does not augur well for any performance improvement intent and is possibly an indication of the lack of readiness of some government establishments for a result-focused M\&E system.

\section{Reaction to Possible Negative Information from the M\&E System}

The need for the determination of how the organisation and employees might respond to possible negative information generated by the M\&E system was important for gauging the preparedness of the organisation for an M\&E system. Arguably, if the organisation and its members would react badly to negative performance information, which is, nonetheless, credible, then that embodies evidence that the organisations are not exactly ready for effective M\&E.

Expectedly, the results of the study with specific reference to this aspect of the M\&E readiness assessment showed that opinions were divided. There were views that expressed the fact that the organisation and its members have the appetite for criticism and would accept, without ill feelings, any negative information generated by the M\&E system. This opinion was informed by the culture of openness and transparency that was in existence in some of the organisations. Furthermore, some respondents argued that the reception of the negative information was because of the fact that there was an air of camaraderie in the organisation, so much so that failures were not personalized but rather accepted because they arise from the shortcomings of the collective workforce.

A contrary opinion suggesting that the organisation and its members were likely to react badly to negative information generated by an M\&E system was also evident from the responses obtained by the study. Majority of the 35 respondents shared this thought.
This points to the fact that the interviewees perceived that their organisations would not be receptive to negative performance information from an $M \& E$ system. Further inquiry revealed that this was the case because any such negative information would have severe ramifications for performance bonuses of employees. Against this background, it becomes increasingly difficult for the M\&E system to generate credible information and so in some cases, even when programmes are not performing, this is not highlighted in the M\&E report. The import of this is that there is no acknowledgement of non-performing programmes and consequently no investment of efforts in trying to ascertain the causes of poor performance, where they exist. The situation smacks of a lack of political will, possibly on the part of the leadership of some of the government institutions to allow the M\&E system to generate performance information without undue interference. It is easy to deduce that the studied organisations with this disposition may not really be ready for an M\&E system.

\section{Capacity for Supporting an M\&E System}

The existence of the requisite capacity that would enable proper functioning of the M\&E system is of utmost importance. Respondents emphasised the need for capacity-building as a means for improving the functioning of the results-based M\&E system. This in itself is an admission of the lack of adequate personnel with the relevant skills to effectively discharge M\&E responsibilities.

Morra Imas and Rist (2009) maintained that a readiness assessment in a particular organization or department is not complete if the current capacity within the said institution or department is not determined. This is clearly, because the system would not work properly in the absence of capacity, particularly as it concerns human resources. The existence of M\&E units in organisations should therefore only be recognized as a first step towards ensuring the generation of accurate performance information that lends itself to improved decisionmaking. Most interviewees highlighted that there are insufficient M\&E practitioners within their organisations and this is a major obstacle to the conduct of M\&E activities. According to some of them, there is a palpable need for the competencies of the few M\&E specialists in these institutions to be complemented by those of experts, drawn from outside of the organization. From the fieldwork, the lack of sufficient capacity for the M\&E system was blamed on the fact 
that government organisations were not currently in positions that permit the recruitment and appointment of new personnel.

Responses also showed that most of the organisations that participated recognised the inadequacy of their capacities to support an effective M\&E system. This makes their preparedness for proper execution of the M\&E function questionable. Instructively though, some respondents volunteered that their organisations had forged collaborations with external experts, especially consultants to help ensure that M\&E responsibilities are adequately discharged. The popular opinion was that capacity could be bought, even if on an ad-hoc basis from academic institutions and other organisations with the relevant expertise. In terms of the type of competencies most solicited from external parties, some respondents indicated that statistical analytical skills and evaluation skills were sought-after regularly but commented these were not easily accessible. This is an indication that people with desirable M\&E skills could be in short supply in the South African labour market. With respect to the specific aim of this study, the lack of capacity testifies to the unpreparedness of the public sector institutions investigated.

\section{The M\&E System as a Link for Project, Programme, Sector and National Goals}

One of the key benefits of an established resultsbased M\&E system is that it seeks to offer a consistent flow of performance information from various sources, across the strata of government. The prospect of linking M\&E systems in government institutions such that there is almost a single coherent and integrated performance information system can be a catalyst for improved service delivery by government. Keeping this type of M\&E system up and running and linking it to goals across local, provincial and national governments requires the tacit buy-in of government officials.

Findings of the current study indicate that respondents insist that the local and provincial goals are linked to the 2030 National Development Plan (NDP) of South Africa. This is the backdrop against which the creation of the government-wide M\&E system (GWM\&ES) becomes meaningful. The claim of some respondents is that M\&E reports are generated with due consideration for alignment-needs within the public service.
While this proposition seems compelling, no respondents could provide evidence as to how the integration across government spheres takes place. Perhaps this goes to emphasize the need for M\&E networking within and across government institutions as a way of ensuring that there is appreciable alignment in sectoral and national goals. Regular meetings with various stakeholders at the sector or national levels could better align both goals and objectives. However, at present, the degree of integration of M\&E efforts and goals across government levels is doubtful. In the face of weak integration of M\&E activities, there could be efficiency leaks in the system that would inevitably deflate the potential of the M\&E system to contribute to overall performance improvement. To some extent, this reflects a shortcoming in the extent of preparedness of some government institutions for the M\&E system.

\section{CONCLUSION AND RECOMMENDATION}

The findings of the study indicate that M\&E systems in a number of public sector institutions have been created in a bid to comply with a mandate from higher authorities or governance expectations in the public sector. This type of foundation for the M\&E system is weak and could compromise the ability of the system to generate meaningful information that would aid decision-making. There is, therefore, a need for a change in the thinking of public sector officials aimed at ensuring higher appreciation of the role of $M \& E$ in the scheme of performance improvement intentions. This weakness in the organizations can be addressed through sensitization of employees about the critical role of M\&E. The success of such sensitization efforts could be enhanced by highlighting the benefits that a good M\&E bodes for the institution. There is, therefore, a glaring need to reposition the M\&E unit in organizations in a way that enables employees and managers alike, better appreciate the role of M\&E. The fact that government officials that are high on the authority hierarchy are predominantly the champions of M\&E systems in their organizations is a good sign of M\&E preparedness. It is important though that these champions support the M\&E system as much as they can.

The responses related to the issue of what may be motivating identified M\&E champions to drive for the establishment of the system reveals that it is largely linked to a desire for performance improvement. This is re-assuring as it implies that the organizations are quite ready for M\&E. It may be necessary, as a way of 
motivating others to support M\&E, to study and generate empirical evidence that corroborates the thinking that good M\&E actions correlate with improved organizational performance. Responses to the ownership question in the readiness assessment exercise expose the current inclination of public sector officials to colonize the M\&E system. While the responsibility for operating the system may lie within the organizations, it is important to sell the idea that the system belongs to a wide pool of stakeholders. In a sense, custodianship is not necessarily collateral with ownership. In order to elevate the value of M\&E information, organizations should always consider performance-related information generated by the M\&E system for the purposes of resource-allocation as well as goals setting.

The mixed findings as it pertains to how organizational members would respond to negative information generated by the M\&E was not unusual and reveals that the studied organizations are not culturally homogenous even though they are all public institutions. Going by the responses gathered, it is evident that while some institutions would allow the M\&E system to generate credible information even if it was negative, others would discourage this. Overwhelmingly, the issue of lack of requisite human capacity for M\&E was identified by respondents. This shortcoming serves to indicate that an important prerequisite of effective M\&E (such as the Human Resources), is inadequate in the studied public sector institutions; the import of which is clear unpreparedness for M\&E. Regardless of this, the view that the $M \& E$ system in organizations seamlessly links goals at different levels of the service delivery chain of government bodes well for M\&E and this merely needs to be strengthened.

Cognizant of the thrust of the current study and its findings, a possible future research could take a critical look at the difficulties that may confront government institutions as they attempt to address issues related to the absence of some of the prerequisites for effective M\&E. It might also be interesting for future research to focus on a comparative analysis of the M\&E readiness of government institutions within and across the three different spheres of government - local, provincial and national.

\section{REFERENCES}

Abrahams, Mark, 2014. A review of the growth of monitoring and evaluation in South Africa: Monitoring and evaluation as a profession, an industry and a governance tool. African evaluation journal, 3(1), 1-8.

https://doi.org/10.4102/aej.v3i1.142
Ataov, Anli and Jawaid, Haider, 2006. From participation to empowerment: Critical reflections on a participatory action research project with street children in Turkey. Children Youth and Environments, 16(2), 127-152.

Behn, Robert, 2003. Why measure performance? Different purposes require different measures. Public Administration Review 63(5), 586-606. https://doi.org/10.1111/1540-6210.00322

Benington, John, and Mark, Moore, 2011, Public value in complex and changing times, in J. Benington and M. H. Moore (eds.), Public Value: Theory and Practice, Palgrave Macmillan, London. https://doi.org/10.1007/978-0-230-36431-8

Boadu, Evans and lle, Isioma, 2017. Rethinking participation in monitoring and evaluation. Beneficiaries' perspectives from the Local Enterprises and Skills Development Programme (LESDEP) in Ghana. Loyola Journal of Social Sciences, 31(2), 209-227.

Cahill, Caitlin, 2007. Doing research with young people: participatory research and the rituals of collective work. Children's Geographies. 5(3), 297-312. https://doi.org/10.1080/14733280701445895

Castro, Fernando, Gladys, Lopez-Acevedo, Gita, Busjeet, and Ximena, Ordonez, 2009. Mexico's M \& E System: Scaling Up from the Sectoral to the National Level. World Bank.

Chouinard, Jill, and Bradley, Cousins, 2013. Participatory evaluation for development: Examining research-based knowledge from within the African context. African Evaluation Journal 1(1), Art. \#43 https://doi.org/10.4102/aej.v1i1.43

Cloete, Fanie, 2009. Evidence-based policy analysis in South Africa: Critical assessment of the emerging government-wide Monitoring and evaluation system. Journal of Public Administration, 44(2), 293-311

Engela, R, and Ajam, T., 2010. Implementing a Government-wide Monitoring and Evaluation System in South Africa, in Independent Evaluation Group (ed.), Evaluation Capacity Development, Working Paper Series 21, World Bank, Washington.

Eresia-Eke, Chukuakadibia, and Okerue, Chijioke, 2018. The nexus of social capital, coping ability and employment creation in African immigrant-owned small businesses. Problems and perspectives in management, 16(3), 311-323 https://doi.org/10.21511/ppm.16(3).2018.25

Gómez, Rafael, Mauricio Olivera, and Mario Velasco., 2009 Implementing Sub-National Results Oriented Management and Budget System: Lessons from Medellin. Colombia ECD Working Paper Series number19. Washington D.C.: The World Bank.

Hauge, Arild, 2001. Evaluation Capacity for M\&E in Uganda: A Result based Management Perspectives. ECD Working Paper Series number 8. Washington D.C.: The World Bank.

Hauge, Arild, 2003. The development of monitoring and evaluation capacities to improve government performance in Uganda. Evaluation Capacity Development Working Paper Series, (10).

Ile, Isioma., Eresia-Eke, Chukuakadibia, and Allen-lle, Charles, 2019 Monitoring and Evaluation of Policies, Programmes and Projects. Van Schaik Publishers: Pretoria

Koranteng, Addo, 2000. Evaluation Capacity Development in Ghana Selected Proceedings of a Seminar and Workshop on M\&E Capacity Development. Johannesburg: The African Development Bank and The World Bank 25-29 December.

Kusek, Jody, 2011. Assessing Country Readiness for Results Based M\&E to Support Results Informed Budgeting. GET Brief, World Bank

Kusek, Jody and Rist, Ray, 2002. Building results based Monitoring and Evaluation System; Assessing Developing Countries Readiness. Zeitschrift fur Evaluation Heft. Vol.1, 151-158 
Kusek, Jody and Rist, Ray, 2003. Assessing Readiness of a national government design and build Results Based M\&E system. A case study of Kyrgyz Republic. The World Bank.

Kusek, Jody and Rist, Ray, 2004. Ten Steps to a Results-Based Monitoring and Evaluation System. The International Bank for Reconstruction and Development / The World Bank: Washington.

Kusek, Jody, Rist, Ray and White, Elizabeth, 2005. How will we know the millennium development goal results, when we see them? Building a results-based monitoring and evaluation system to give us the answers. Evaluation, 11(1), 7-26. https://doi.org/10.1177/1356389005053181

Lahey, Robert, 2005. Moving Towards Results-Based Performance Measurement: Building M\&E Capacity in ASEZA: Phase 1: Discovery phase. ASEZA: USAID.

Mackay, Robin, 2007. How to Build M\&E Systems to Support Better Governance. The World Bank, Washington D.C. https://doi.org/10.1596/978-0-8213-7191-6

Matsiliza, Noluthando, 2012. Participatory monitoring and evaluation: Reviewing an inclusive approach in the South Africa's government wide monitoring and evaluation. Africa's public service delivery and performance review, 1(2), 67-83 https://doi.org/10.4102/apsdpr.v1i2.31

Morra Imas, Linda, and Rist Ray, 2009. The Road to Results: Designing and Conducting Effective Development Evaluations. The World Bank: Washington DC https://doi.org/10.1596/978-0-8213-7891-5

Pares, Albert, 2006. The Plano Plurianual and M\&E in Brazil. In May, E., Shand, D., Mackay, K., Rojas, F. and Saavedra, J., Towards the Institutionalisation of M\&E Systems in Latin America and the Caribbean: Proceedings of the World Bank/Inter-American 85 Development Bank Conference (2127). Washington D.C.: The World Bank \& Inter-American Development.
Plaatjies, Daniel, and Stephen, Porter, 2011. Delivering on the Promise of Performance Monitoring and Evaluation, in D. Plaatjies (ed.), The Future Inheritance: Building State Capacity in Democratic South Africa, 292-312, Jacana, Johannesburg.

Porter, Stephen, and lan, Goldman, 2013. A Growing Demand for Monitoring and Evaluation in Africa. Africa Evaluation Journal 1(1), Art. \#25, https://doi.org/10.4102/aej.v1i1.25

Schiavo-Campo, Salvatorre, 2005. Evaluation Capacity Development: Building Country Capacity for M\&E in the Public Sector: Selected Lessons of International Experience. ECD Working Paper Series number 13. Washington D.C. The World Bank.

Scott, Leanne, Joubert, Alison and Anyogu, Akaolisa, 2005. Setting National Goals, M\&E: A Comparison of Approaches across Selected Countries. Working paper number 2. Retrieved from www.thepresidency.gov.za/docs/pcsa/me/comparison/part1. pdf [9th March 2019]

Segone, Marco, 2000. Sustainable M\&E Capacity Development in Africa: The Case of the M\&E Network in Niger. Selected proceedings from a seminar and workshop on M\&E capacity development. Johannesburg: DBSA, The African Development Bank and The World Bank.

United Nations Development Programme (UNDP), 2009. Handbook on Planning, Monitoring and Evaluating for Development Results. UNDP: New York.

Wagner, Daniel, Bob Day, Tina James, Robert Kozma, Jonathan Miller and Tim, Unwin, 2005. Monitoring and evaluation of ICT in education projects. A handbook for developing countries. A Handbook for Developing Countries. Washington DC: InfoDev/World Bank.

\section{DOI: https://doi.org/10.6000/1929-7092.2019.08.46}

(c) 2019 Eresia-Eke and Boadu; Licensee Lifescience Global.

This is an open access article licensed under the terms of the Creative Commons Attribution Non-Commercial License (http://creativecommons.org/licenses/by-nc/3.0/) which permits unrestricted, non-commercial use, distribution and reproduction in any medium, provided the work is properly cited. 